\title{
An Analysis of the C-E Translation of Public Signs in Shaolin Temple from the Perspective of Functionalist Theory
}

\author{
Shuai CHEN \\ School of Foreign Languages \\ Huanghe College of Science and Technology \\ Zhengzhou, 450063, China
}

\begin{abstract}
- with the rapid development of the world economic globalization, the communication between china and other nations becomes wider and more frequent, and more and more foreigners have come to China to travel. In order to meet the needs of foreigner tourists, many public signs have been translated into English, which is of great significance to international communication and offers great convenience for foreign friends. However, some English translations of public signs in scenic spots are far from being satisfactory and even confusing, which have a bad influence on the image of the Chinese people. Based on the Chinese-English bilingual public signs in Shaolin Temple scenic spot, the author, in this paper, puts forward what should be paid attention to in the process of public signs' translation from the perspective of Functionalist Theory.
\end{abstract}

Keywords- Functionalist Theory; scenic spots; public signs; English translation

\section{INTRODUCTION}

With the rapid development of the world economic globalization, the communication between china and other nations becomes wider and more frequent. More and more foreigners have come to China to travel, study and do business, etc. the National Bureau of Statistics of China reveals that the total number of overseas visitors tops 26 million in 2009. And Shaolin Temple, as the birthplace of Chinese Kungfu, is a big attraction to all the tourists at home and abroad. According to Dengfeng travel bureau, more than 5000 people visit Shaolin Temple each day, the ticket income reaches more than 150 million in 2007, and the total revenue brought by visitors come up to more than 3.7 billion in 2007, and what is important is nearly tens of thousands of foreign visitors pay a visit to Shaolin Temple each year, including Putin (the present president of Russia), Kissinger (the former Secretary of State in the United States) and so on. In order to cater to the needs of foreigner tourists, ChineseEnglish bilingual public signs come into being in many scenic areas of Shaolin Temple more and more public signs have been translated into English, which is of great significance to international communication and offers great convenience for foreign friends. However, some English translations of public signs are far from being satisfactory and even confusing, which have a bad influence on the image of the Chinese people. The inappropriate or even incorrect English translations of public sign can not achieve the function of successful communication; they also make a bad contribution to the image of China, which is very difficult for the Chinese to accept. So it is of great significance to do the research of Chinese- English translation of public signs, and this task is also very urgent.

\section{OVERVIEW OF FUNCTIONAL TRANSLATION THEORY}

Functionalist approaches to translation are very influential trend in modern translation studies. They were developed in Germany in the late 1970s. It was not until it went through four stages that it came into being as a whole. Katharina Reiss, Hans J. Vermeer, Justa Holz-Manttari and Christiane Nord are prominent figures of the school.

The core of the Reiss theory is text typology. She divides the semantic function of language into "informative text", "expressive text", and "operative text" according to the characterization of functional language. And according to Reiss, in the process of translation, the translator should first determine the type of text, and then choose the translation method; translation methods should be consistent with the text types.

Vermeer's skopos theory is the most important theory of the Functionalist Approach. The term "skopos" comes from Greek, which means the aim or purpose of a translation. The theory holds that translation is a behavior with purposes and results source text, and this behavior must be accomplished through consultation; translation must follow a series of laws, among which the skopos law should be put in the first place, that is to say, the translation depends on the purpose of translation. In addition, the translation should follow the intratextual coherence rule and the intertextual coherence rule.

Justa Holz-Manttari who goes one step further than Vermeer and moves away from the traditional concept of translation on the basis of Vermeer' s Skopostheorie, put s forward "translational action", and the purpose of translational action is to transfer messages across culture and language barriers. In her model, translation is defined as "a complex action designed to achieve a particular purpose". She further develops functionalist approach to translation. By even avoiding the term "translation" in the strict sense, she prefers to use 'message transmitters'. Based on the principles of action theory, her theory of translational action is designed to cover all forms of inter-cultural transfer, including those 
which do not involve any source or target texts. In her model, translation is defined as "a complex action designed to achieve a particular purpose" in a much broader sense than any other previous translation theories. In this sense, translation includes all translational actions intended to transfer messages across cultures and language barriers by experts, which is an intentional action rather than a mere transcoding procedure.

Christiane Nord, an important figure of the German school of functionalist translation theory, published Translating as a Purposeful Activity (1997), which explains the development and the basic concepts of functional theories of translation in English. She points out the limitations of Vermeer's skopos theory and attempts to refine Vermeer's model by putting forward her own functional model: "function plus loyalty" on the basis of former achievements. She defines translation as the production of a functional target text maintaining a relationship with a given source text that is specified according to the intended or demanded function of the target text. As one of the major initiators of functionalist theory in Germany, Christiane Nord further opened up the theory and by putting forward "function plus loyalty" model on the basis of former achievements. She defines translation as the production of a functional target text maintaining a relationship with a given source text that is specified according to the intended or demanded function of the target text.

\section{An ANALysis of Public Signs In SHaOlin TEMPle FROM THE PERSPECTIVE OF FUNCTIONALIST TRANSLATION THEORY}

Functionalist translation theory stresses that the translation strategy should be selected according to the intended purpose and function of the target text. Based on Reiss' text typology, scenic public signs belong to informative and operative text. Scenic public signs aim to inform visitors of relevant information or tell them not to do something. Therefore, the translation of scenic public signs should follow the principle of "Readers First", and due consideration should be given to the target readers in the process of translation. Translators should respect the cultural habits of target readers, combining the language features and functional meanings of scenic public signs and choosing appropriate translation strategies.

\section{A. Improper diction}

According to Longman Dictionary of English Language \& Culture (2004), the word "diction" means "the choice of words and phrases to express meaning. And in translation, diction means the appropriate choice of words in the target text based on correct understanding of the source text. The author presents some translation problems and errors, which are caused by wrong diction, in the English public signs of Shaolin Temple. For instance,

Example 1: Emergency Entrance

The word "entrance" means the act of entering, according to Webster, s Dictionary. It emphasizes "entry" . So usually it is translated as: Emergency Exit.
Example 2: Puxian is the right attendant of the Buddha and also the Bodhisattva on behalf of the theory and the practice of Buddihism.

According to "Longman Dictionary of Contemporary English", "attendant" refers to "a person employed to look after and help visitors or customers in a public place". However, Buddha is the "right arm" rather than "the waiter." Therefore, I propose that "right attendant" should be changed into "a good assistant" or "a big help".

\section{B. Chinglish}

Because of different ways of thinking, many public signs translation in Shaolin Temple are Chinglish, which is very confusing to foreign tourists and can not achieve the function of public signs, causing damage to the image of the Chinese nation.

Example 3:

Ban on down to the river

Pay attention to safety

This word-word translation fails to reach the function of warning visitors, the intention can be embodied in "Danger: Deep water!"

\section{Cultural misunderstanding}

Language is the carrier of culture, so the application of language must take into account its cultural connotation, otherwise it will have a negative impact on the semantics conveyed. Some public signs, such as "the goods that have been sold shall not be returned," "it is strictly prohibited to defecate indiscriminately", are commonplace for the Chinese people, but this kind of information does not exit in Englishspeaking countries. If these public signs are directly translated into English, it will cause misunderstanding from foreign tourists.

Example 4: Do not arbitrary leave the feces or urine anywhere.

The word "arbitrary" is not correctly used in this translation, and this sign is very vulgar in a beautiful scenic environment, it is very difficult for foreign tourists to accept and it will have a negative impact of Chinese international image. Therefore, I propose this kind of public signs should not be translated into English or other languages.

\section{CONCLUSIONS}

Every theory has its limitations, and skopostheorie is not an exception. It is not a panacea able to guide all the translating of Chinese public signs into English. However, Skopostheorie together with text typology has helped to bring the target text into focus, bringing innovation to translation theory. Its principles of translation have come to be viewed as target-text authors and have been released from the limitation and restriction imposed by a narrowly defined concept of loyalty to the source text alone. So the translator's responsibility for target language readers is the criterion in sign translation within the framework of Skopostheorie. This makes contribution to the standardization and regulation of translation on public signs. Although public signs in scenic spots tend to be short and simple, just containing a few words, however, their translation is by no means easy. 
Putting them into appropriate English is never an easy task. It falls into the practical texts and its translation should be target reader-centered. To present a favorable image of China and achieve better communication with the outside world, much emphasis should be put on the translation of the public signs. Now more and more people have come to realize the importance of the public signs translation. The holding of The Second Symposium on C-E Signs in a Global Context in Tongji University on July 14th-15th, 2007 is an indication. We are of confidence that the quality of C-E sign translation will get better in the near future..

\section{ACKNOWLEDGEMENTS}

Fund Project: This article is the stage research result of the following project: the standardized construction research of public signs translation in Henan under the international background (ID: 142400410118), a project approved Henan province department of science and technology in 2014.

\section{References}

[1] Nord, Christiane. Translating as a Purposeful Activity: Functionalist Approaches Explained [M].Shanghai: Shanghai Foreign Language Education Press, 2001.

[2] Longman dictionary of contemporary English [Z], Beijing: Foreign Language Teaching and Research Press, 2003.

[3] Reiss, k. Translation Criticism: Potential and Limitations [M], Manchester: St Jerome and American bible society, 2000.

[4] Leech, Geoffrey N. Principles of Pragmatics [M],London: Longman group Ltd, 1983.

[5] Basil Hatim. Teaching and Researching Translation [M], Beijing: ForeignLanguage Teaching and Research Press, 2001

[6] Bell, R. T. Translation and Translating: Theory and Practice [M]. London and New York: Longman, 1991.

[7] Dann, G. M. The Language of Tourism: A Sociolinguistic Perspective. [M].Wallingford: CAB International, 1996

[8] Gentzler Edwin. Contemporary Translation Theories [M]. Shanghai: Shanghai Foreign Language Education Press, 2004.Li Peie. Translation attractions name [J], "Wuhan Vocational and Technical College" 2004 (2)

[9] Wilss, W. The Science of Translation: Problems and Methods [M], Shanghai: Shanghai Foreign Language Education Press, 2001.

[10] Newmark, Peter. Approaches to translation [M], Shanghai: Shanghai Foreign Language Education Press, 2001. 